Revista Internacional de Apoyo a la Inclusión, Logopedia, Sociedad y Multiculturalidad.

Volumen 7, Número 1, enero 2021, ISSN: 2387-0907. DOI: https://dx.doi.org/10.17561/riai.v7.n1.11

\title{
Mulheres em rede de saberes vivenciando a comunidade caiana dos crioulos e reexistindo na luta
}

Women in a network of knowledge experiencing the caiana community of criollos and reexisting in the struggle

Frauen in einem Netzwerk des Wissens, das die Gemeinschaft der Criollos erlebt und sich im Kampf wiederfindet

Des femmes dans un réseau de connaissances qui vivent la communauté caiana des criollos et qui se réinsèrent dans la lutte

Donne in una rete di conoscenze che sperimentano la comunità caiana dei criollos e rivivono nella lotta

Женщины, объединенные в сеть знаний, переживают общину криоллосов кайаны и вновь вступают в борьбу.

クリオロスのカイアナ・コミュニティを経験し、闘争の中で再存在する知識

のネットワークの中の女性たち

知识网络中的妇女经历了caiana criollos 社区, 并在斗争中重新存在。

\author{
Luciene Tavares da Silva Lima \\ Universidade Estadual da Paraíba-PPGFP(Brasil) \\ lucienebelezanegra@hotmail.com \\ Patrícia Cristina de Aragão \\ Universidade Estadual da Paraíba-PPGFP (Brasil) \\ patriciacaa@yahoo.com
}

Fecha recepción:16/10/2020

Páginas 136-150

Fecha aceptación:29/12/2020

\section{Resumo.}

As mulheres negras de comunidade quilombolas têm um lugar significativo na luta social, cultural das práticas desenvolvidas na comunidade. No contexto da comunidade negra de quilombo de Caiana dos Crioulos na cidade de Alagoa Grande -PB, as mulheres negras desta comunidade, tem um papel fundamental na articulação social da trajetória histórica da comunidade. As mulheres em redes de saberes, constroem as vivências e experiências cotidianas da comunidade, empreendendo sua luta antirracista através da resistência diária e na reexistência enquanto sujeito de direito, humano e social. Este artigo, tem como objetivo discutir sobre a atuação de mulheres negras de Caiana de Crioulos apresentando um breve percurso de atuação e ação na comunidade. Trata-se de um artigo de reflexão sobre os lugares de pertencimento das mulheres desta territorialidade negra e seus campos de práticas sociais. Se configura como uma pesquisa bibliográfica e documental, em que a análise realizada partiu de reflexões e ações desenvolvidas pelas mulheres do quilombo. Consideramos que a luta das mulheres negras dentro/fora da comunidade Caiana apresenta-se como um importante potencial para representar as mulheres quilombolas em suas reexistências cotidianas. 
Palavras-chave: mulher negra; quilombo; rede de saberes; práticas

\begin{abstract}
.
Black women from quilombola communities have a significant place in the social and cultural struggle of practices developed in the community. In the context of the quilombo black community of Caiana dos Crioulos in the city of Alagoa Grande -PB, the black women of this community play a fundamental role in the social articulation of the historical trajectory of the community. The women in networks of knowledge, build the daily lives and experiences of the community, undertaking their antirracist struggle through daily resistance and in the re-existence as a subject of right, human and social. This article aims to discuss the work of black women from Caiana de Crioulos, presenting a brief journey of work and action in the community. It is an article that reflects on the places where women from this black territoriality belong and their fields of social practices. It is configured as a bibliographic and documental research, in which the analysis carried out started from reflections and actions developed by the women of the quilombo. We consider that the struggle of black women within/out of the Caian community presents itself as an important potential to represent quilombola women in their daily reexistances.
\end{abstract}

Keywords: black woman; quilombo; network of knowledge; practices

\title{
1.-Introdução.
}

\section{Para inicio de conversa....}

A história das mulheres negras de quilombo é marcada por lutas, resistências e transposições de fronteiras. Fronteiras educativas, sociais, culturais e políticas, mas, contudo, através dos tempos a mulher negra quilombola, foi rompendo grilhões de preconceitos e mesmos diante dos limites impostos e das opressões, souberam como romper com estas condições postas e delinear os seus saberes e fazeres próprios de sua interpretação do mundo, das pessoas e lugares de seus pertencimentos sociais, suas vivências e experiências foram importantes na construção de suas práticas sociais e culturais e sobretudo, na luta contra opressão diante das discriminações sociais para o povo de quilombo.

Observamos que no âmbito da sociedade brasileira as mulheres negras de quilombo, foram reescrevendo suas histórias na reexistência de suas práticas sociais, culturais e políticas, marcando e demarcando seus territórios de pertenças e suas identidades étnico-raciais, representando assim, uma força na luta e nos seus próprios trajetos, pois, enquanto sujeito humano e social foram semeando vários ensinamentos em torno de sua afirmação identitária, sobre o que consistia em ser negra, mulher e quilombola. ${ }^{1}$

1 Graduada em Pedagoia pela Universidade Estadual Vale do Acaraú- UVA. Pós- Graduada em Psicopedagogia pela Faculdades Integradas de Patos- FIP. Mestranda no curso de Pós-Graduação em 
No território quilombola, a mulher negra tem um papel fundante na construção e reconstrução de lutas e trajetórias, pois através das participações sociais e engajamento político, a mulher negra enquanto sujeito político, procura faz sentido no que se refere a sua luta diária dentro e fora da comunidade, pois o seu empenho, possibilita pensar um posicionamento afrocentrado nas questões sociais que permeiam a comunidade na qual habita.

Neste artigo propomos refletir sobre as práticas desenvolvidas pelas mulheres negras da comunidade quilombola de Caiana dos Crioulos no município de Alagoa Grande - Paraíba, Brasil, através da atuação destas em redes de ações e saberes mediatizados a partir da Organização das mulheres negras de Caiana - OMNC, uma ong que busca lutar pelas demandas da comunidade.

Enfatizamos neste itinerário reflexivo as ações praticadas e propostas pela Organização das Mulheres Negras de Caiana - OMNC, e sua importante ação de referência no espaço comunitário, cuja relevância e contribuição tem sido fundamental nas articulações políticas e sociais que a na comunidade são desenvolvidas. O objetivo é discutir sobre a atuação de mulheres negras de Caiana de Crioulos apresentando um breve percurso de atuação e ação na comunidade.

Esta comunidade quilombola está localizada no Município de Alagoa Grande no estado da Paraíba/Brasil e foi reconhecida pela Fundação Cultural Palmares em maio do ano 2005 como $013^{\circ}$ quilombo do Brasil, é considerada o maior quilombo no estado da Paraíba.

Trata-se de um artigo de reflexão sobre os lugares de pertencimento das mulheres desta territorialidade negra e seus campos de práticas sociais, em que busca problematizar a força do povo de quilombo traduzida na ação social, política e cultural das mulheres negras, como estas nas suas lutas trazem a marca histórica e social de sua comunidade.

O século XX foi um marco no desbravamento da mulher negra de quilombo, por novos itinerários sociais, em que ela se situou enquanto sujeito político, diante das intempéries vivenciadas em seu cotidiano. Este período também se notabilizou como um momento de reinvenção da mulher negra e suas experiências políticas, educacionais e culturais, na criação de novos horizontes e itinerários de percepção do social para as populações negras de quilombo no Brasil.

Educadas para o silêncio muitas mulheres não se emudeceram, pois no silêncio de suas reflexões passaram a ecoar seus gritos de liberdade. Suas vozes, muitas vezes

Formação de Professores da Universidade Estadual da Paraíba- UEPB. E-mail para contato: lucienebelezanegra@hotmail.com

2 Patrícia Cristina de Aragão, possui Graduação em Psicologia pela Universidade Estadual da Paraíba (1989), Graduação em História pela Universidade Federal da Paraíba (1990), Mestrado em Economia pela Universidade Federal da Paraíba (2001) e Doutorado em Educação pela Universidade Federal da Paraíba (2007). Atualmente é professora titular da Universidade Estadual da Paraíba, atuando no curso de História, no Mestrado Profissional em Formação de Professores e no Mestrado de Serviço Social. E-mail para contato: patriciacaa@yahoo.com 
cerceadas, buscaram e buscam empreender um processo social pela igualdade de gênero, por seus direitos e a construção de suas identidades.

As mulheres negras de quilombo na contemporaneidade, forjaram no cotidiano, tanto no espaço público como no privado, um jeito de ser mulher, negra e quilombola e fazer história, reescrevendo esta história mesmo diante de padrões sociais podadores de suas atitudes, de suas condições sociais, de seus marcadores identitários de etnia, geração, cultura e política. No contexto da luta das mulheres quilombolas é fundamental ressaltar, o lugar destas nas conquistas sociais e políticas dentro das suas comunidades.

Falar de negritude, da construção da identidade negra de quilombo é sumamente importante, para desconstruir não somente estereótipos e estigmas socialmente elaborados, mas sobretudo, mostrar as histórias vividas, das práticas construídas, da forma como no construto social, o povo negro quilombola e nele as mulheres reconstruíram suas histórias em narrativas e práticas através dos tempos, procurando nos seus modos de vida e na forma como desenvolveram e desenvolvem seus trabalhos, mostrar a força de sua luta e das conquistas realizadas, no fortalecimento social e político dentro do território quilombola.

Metodologicamente, nosso itinerário reflexivo partiu de um olhar sobre a experiência das mulheres de Caiana na comunidade, a partir da organização por elas criadas, a OMNC, bem como da prática do turismo local, na busca do desenvolvimento local e da sustentabilidade da comunidade diante dos enfrentamentos sociais que permeiam a vida comunitária. Trata-se de relato de experiência que se articula a uma pesquisa bibliográfica e documental, que veio dar respaldo a nossa proposta, na discussão dos saberes que são construídos na comunidade.

\section{2.-Entre o texto e o contexto: mulheres negras de caiana dos crioulos na luta e reinvenção identitária.}

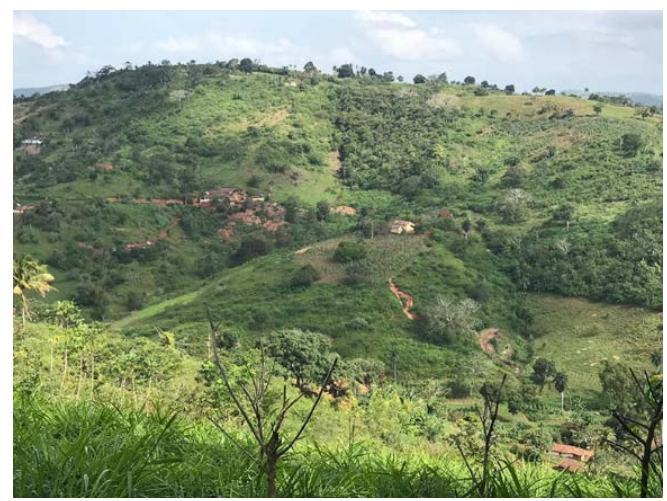

Figura1: Vista de uma parte da Comunidade Quilombola Caiana dos Crioulos(Acervo pessoal de Luciene Tavares).

A imagem acima, mostra uma breve panorâmica da comunidade quilombola de Caiana de Crioulos, nesta comunidade as mulheres buscam atuar de modo a 
estabelecer uma reinvenção da vida no território, desenvolvendo práticas sociais e políticas que busquem o bem-viver comunitários, em que a vida floresça, em que a justiça social para o povo de quilombo aconteça.

No território de Caiana dos Crioulos, são múltiplas as histórias de mulheres negras que buscam nas suas ações diárias, desenvolver o ativismo político e social na comunidade. Viver na comunidade, é também buscar articular-se para resistir e existir frente os embates sociais que trazem reflexos no território.

No contexto da luta das mulheres negras quilombolas é fundamental ressaltar, 0 lugar destas na nas conquistas sociais e políticas dentro das comunidades. A luta feminista e pelos direitos das mulheres tem sido debatida há muitos anos e as mulheres negras no âmbito da luta do movimento feminista negro, tem dado seu contributo social, para pensar o lugar de fala da mulher negra e lutar pelo reconhecimento social e político das mulheres negras, no fortalecimento de sua identidade étnica. (Morais,2018; Crenshaw, 2002).

Trazer à tona 0 debate em torno de uma perspectiva interseccional e decolonial das questões raciais no Brasil, é primordial, sobretudo, quando na contemporaneidade as pautas das mulheres negras em movimento, frente as desigualdades crescentes que se apresentam no painel social do Estado brasileiro, tem se ampliado focalizando as demandas sociais, culturais, educacionais e de políticas para o território.

Segundo Costa, os movimentos sociais e/ou grupos sociais de resistência/subalternos rurais e urbanos constituem-se enquanto sujeitos que vivenciam a decolonialidade, pois, são produtores de conhecimento, a partir, dos seus fazeres, saberes e resistências frente ao capital. Segundo Escobar (2010) esses indivíduos se forjam por meio do conhecimento, enquanto ferramenta de luta por equidade. $\mathrm{Na}$ atualidade estes sujeitos decoloniais, passaram a pesquisar/produzir conhecimento, a partir do seu lugar de fala. (Costa, 2018, p.11).

Se durante muito tempo a pauta voltada para a mulheres negras estava ausente do debate dentro do movimento feminista, a mulheres negras ao questionarem e lutarem por esta inclusão possibilitaram outras perspectivas para pensar o próprio trajeto do feminismo no Brasil.

Foi a partir da ação das mulheres negras, como agentes sociais, que desenvolvendo tecnologias sociais de ação comunitária na busca da justiça social para o povo negro de quilombo, que as pautas das mulheres negras passaram a integrar as bandeiras de luta do movimento feminista negro e coletivos de mulheres negras, importantes segmentos sociais e políticos.

As mulheres negras trouxeram importantes propostas para 0 movimento social feminista, entre as quais chamaram atenção as especificidades das mulheres negras no contexto da sociedade brasileira, e apresentando a historicidade de suas lutas 
históricas desde a diáspora africana até a o pós-abolição e as reinvindicações contemporâneas.

Diante da violência histórica e a invisibilidade social, a mulheres negras em movimento chamaram atenção no enfoque do movimento social feminista negro, a saúde, educação, políticas sociais de empregabilidade, políticas culturais para as populações negras. Dentro das distintas realidades, estão as mulheres negras e quilombolas, lutando por sua população, por seu lugar de pertencimento social, político, cultural, histórico e étnico.

Este texto conforme já ressaltamos anteriormente, apresenta nossas reflexões em torno da comunidade Caiana dos Crioulos e a organização das mulheres negras que nela atuam, mostrando assim a força na busca das reexistências quilombolas. Estas mulheres mantém toda a sua cultura, trabalhando na valorização da mesma, mantendo viva as práticas em torno de seus cultos e desenvolvendo seus rituais como faziam seus ancestrais.

Além de atentar-se ao fazer cultural, a comunidade tem suas formas de organização social, e as mulheres são atuantes no território, a partir dos trabalhos desenvolvidos na comunidade. As mulheres negras da comunidade buscaram reinventar-se no território através de articulações internas com a militância e a partir das organizações dos grupos existentes na localidade.

A partir da organização interna, fruto da socialização e discussões dos problemas comunitários e de busca de ações coletivas que pudessem trazer contributos para a territorialidade, surgiu em 2005 a OMNC- Organização de mulheres Negras de Caiana, uma organização não governamental da sociedade civil, sem fins lucrativos, que tem como objetivo contribuir para o crescimento pessoal e grupal das mulheres de Caiana. Esta organização é importantíssima na criação de ações sociais que veiculem o tratamento dos direitos sociais da comunidade.

A organização luta contra formas correlatas de racismos, dentro de uma política interna e externa da prática do antirracismo, para a eliminação do racismo e sexismo, bem como promover ações que fortaleçam a identidade étnico-racial, 0 empoderamento e auto-estima das mulheres negras no quilombo.

A OMNC tem parceria externa a comunidade, que é formada a partir da BamidelêOrganização de Mulheres Negras na Paraíba, cuja interfaces e articulações são importantes tanto na conscientização comunitária, como no efetivo de luta por política social e justiça para os direitos do povo de quilombo, e também contribui na formação social e cultural das mulheres da comunidade principalmente na questão de formação.

A partir da relação com a Bamidelê foram criados laços com outra organização não governamental, como é o caso da Cunhã- Coletivo feminista cujas articulações na 
comunidade, permitiram elaborar pautas voltadas o povo negro de quilombo e em especifico, com foco nas ações mulheres negras.

Através das ações desenvolvidas pela OMNC, ampliou-se o diálogo sobre as várias dificuldades enfrentadas no quilombo e como estas pontuam implicações na vida de cada morador/a de Caiana dos Crioulos, sobretudo das mulheres, entre as quais destacamos a negação de direitos, políticas públicas de reparação e inclusão.

As mulheres de Caiana dos Crioulos, nem sempre tiveram seus empoderamentos, e há 20 anos, poucas delas conheciam o espaço externo (fora do quilombo), pois dedicavam-se apenas a cuidar da casa, dos filhos, e ao trabalho agrícola. A maioria delas não eram alfabetizadas e as que tinham acesso ao ambiente escolarizado, trajetavam até 0 ensino fundamental, pois, desconheciam seus direitos e quando esses eram violados não sabiam nem mesmo aonde ou a quem poderia recorrer. Mas esta situação foi modificando, tanto internamente, como externamente através das articulações sociais e políticas que foram empreendidas, o que resultou num importante avanço para o campo de atuação da mulher de Caiana.

A relação e articulação com a Bamidelê, trouxe transformações na Comunidade Caiana dos Crioulos, visto que, mudou muito na vida das mulheres do ponto de vista das ações políticas, engajamento social e formação educacional, estas ultimas, por exemplo, foram fundamentais na construção desta parceria que buscou trabalhar em torno do protagonismo feminino na comunidade.

A partir destas formações as mulheres da comunidade participantes da OMNC, passaram a atuar mais amplamente, na busca sobretudo, de políticas públicas enfatizando os direitos sociais do povo da comunidade. Os incentivos dados, foram fundamentais também, para que muitas mulheres da comunidade pudessem dar continuidade aos seus estudos, mesmo diante das dificuldades da vida cotidiana, pois, estas mulheres ao serem conhecedoras de seus direitos engajaram-se na luta pela desconstrução do racismo, preconceito e estereótipos voltadas para a sua população.

A figura 2 abaixo apresenta uma reunião de mulheres de Caiana, participantes da OMNC e a Bamidelê, organizando-se para participar da Marcha das Mulheres Negras em 2015, esta participação foi fundamental nas ações da organização da comunidade e na interface de saberes construída com outras mulheres negras quilombolas ou não. Participar da marcha, representou um avanço na luta das mulheres da comunidade. 


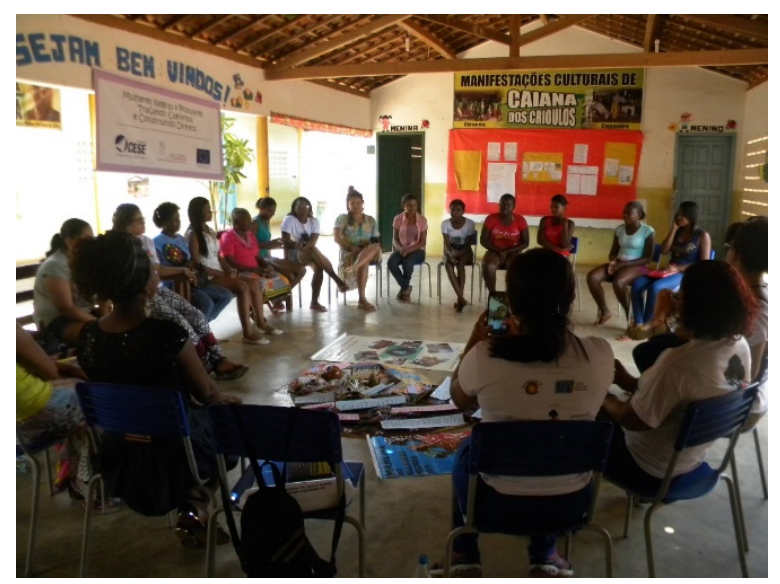

Figura 2: Bamidelê e a OMNC em Oficina de Preparação à Marcha das Mulheres Negras 2015. (Acervo pessoal de Luciene Tavares.

É importante ressaltar que a Organização de Mulheres Negras, desenvolveu nos encontros realizados, o debate em torno das problemáticas da comunidade, havia todo um cuidado no sentido de discutir as demandas da comunidade, como é o caso da educação, saúde, desenvolvimento social entre outros.

Os debates promovidos giravam e giram em torno de como as ações do poder local e estadual trabalha em função dos direitos e demandas do povo quilombola e como na realidade de Caiana dos Crioulos tais direitos são enfatizados.

A partir do potencial que a comunidade apresenta, tais como as práticas culturais, sociais, a historicidade começou-se a organizar ações para o desenvolvimento local e o turismo rural foi um meio encontrado em Caiana dos Crioulos. Este quilombo, sempre teve um potencial turístico, porém as pessoas da comunidade não haviam despertado para o mesmo, mas sempre recepcionava as pessoas que chegavam no território, principalmente pesquisadores e estudiosos da temática quilombola.

A OMNC observando o potencial turístico da comunidade, começou a se articular, na elaboração de roteiro turístico, em que nele havia todo um catálogo cultural e histórico da comunidade. Isto foi feito, em função de que se verificou que durante muito tempo a comunidade acolhia pessoas vindas de fora e que estas tinham estadia e colaboração das pessoas da comunidade, buscavam informações e conhecimento sobre a mesma e não traziam retorno que pudesse empreender 0 desenvolvimento local e social, diante destes e outros aspectos da demanda comunitária, buscou-se dar visibilidade as práticas culturais comunitárias.

Mas foi pensando em solucionar problemas tais como: evasão em massa dos jovens da comunidade e o fato de que algumas famílias da comunidade migravam de Caiana em busca de oportunidades de trabalhos que o município não oferecia que a OMNC através da ação de três mulheres integrantes da organização: Elza Ursulino, 
Maria das Dores e Luciene Tavares em parceria com pessoas do grupo de ativismo cultural do Município de Alagoa Grande na Paraíba, começaram a empreender ações em torno de efetivar o turismo rural.

Este tipo de atitude, provocou mudanças na comunidade, em que a permanência dos jovens e familiares era a pilastra para que a organização pudesse trabalhar em torno do incentivo, divulgação e efetivação do turismo na comunidade.

O debate em torno desta ideia encontrou eco, quando o grupo de reuniu em 2015, com o produtor Cultural Eudes Vidal, que na época estava à frente da Secretaria de Cultura Local, dialogava com essa possibilidade, pois era comum a comunidade está presente em apenas alguns momentos culturais desenvolvido na cidade, e quando isso acontecia, era representada por algum grupo do quilombo e só.

Foi, portanto, a partir da ação coletiva que se iniciou o trajeto em torno de um projeto que daria força para que as atividades turísticas no local pudessem ser desenvolvidas, o que permitiu a esta abertura comunitária foi a proposta empreendida pelo Projeto Vivenciando Caiana.

Este projeto redimensionou as práticas culturais da comunidade, oportunizando aos seus moradores de mostrarem os saberes e fazeres deste território, a partir de um projeto que pretendia na época, apresentar a comunidade a partir de seus valores culturais, sociais e histórico. O Vivenciando Caiana, é um projeto voltado para 0 turismo rural quilombola de base comunitária.

O projeto surgiu em 2016, quando lideranças da comunidade se reuniu com algumas pessoas da cidade Alagoa Grande que compõe um grupo chamado "Articulações Sociais de Alagoa Grande", um grupo informal que tem o objetivo de tratar das questões sociais do município, estas interfaces entre as lideranças da comunidade e os integrantes do grupo de articulações sociais, permitiu que o turismo no território quilombola, contribuiu para a realização deste projeto e favorecesse as pessoas da comunidade.

Para o primeiro encontro que veio culminar na efetivação do Vivenciando Caiana, estiveram presentes algumas lideranças da comunidade como: Elza ( agente comunitária de saúde), professora Maria das Dores ( Neide - Quilombola local), professora Luciene Tavares ( professora da Escola Firmo Santino na época); já da cidade estiveram presentes: Professoras Lúcia de Fátima Júlio (que havia sido gestora da escola supracitada); O professor Gustavo (Guto - professor da cidade de Alagoa Grande), Nazareno Félix ( Membro do Banco do Nordeste) e Marcelo Félix (da empresa de Internet local Avexado.com).

Foi uma reunião, na qual foram feitas colocações apontando os objetivos para 0 desenvolvimento da comunidade quilombola, como também para trabalhar na desconstrução do racismo perante a sociedade. A partir deste momento foi marcado uma segunda reunião na comunidade, que aconteceu em uma das salas de aula da Escola Firmo Santino da Silva, escola da comunidade, onde a gestora da época, 
professora Josiane Brito do Nascimento e Sousa, recepcionou a ideia para 0 desenvolvimento local.

$\mathrm{Na}$ segunda reunião outras lideranças se juntaram ao grupo para dar início ao projeto, e marcaram presença: Elza; Severina Luzia (Cida- Na época, presidente da associação), Lourdes ( auxiliar de serviços gerais da Escola Firmo Santino), professora Maria das Dores ( Neide); Edite José da Silva ( Coordenadora do Grupo de Ciranda Edite do Coco); e por mim, professora Luciene Tavares; já da Cidade estiveram presentes: Professoras Lúcia de Fátima e Josiane Brito (a primeira, anterior gestora da escola supracitada, e a última atual Gestora da mesma); 0 professor Gustavo ( Guto - professor da cidade), Nazareno Félix ( Membro do Banco do Nordeste), Eudes Vidal (Dedeu)- Produtor Cultural, e Fabrício Fortunato (amigo da comunidade e também Vereador do Município).

Foi a partir deste segundo encontra que lideranças da comunidade participaram do projeto, contribuindo e reforçando a ideia do projeto Vivenciando, a senhora Edinalva Rita e o senhor Antônio do Nascimento (Totinha) entre outras pessoas que passaram a colaborar no projeto Vivenciando.

O projeto Vivenciando Caiana trabalha na promoção do desenvolvimento cultural, econômico e social da Comunidade Caiana dos Crioulos, valorizando todos os saberes tradicionais, a memória e a identidade dos quilombolas. Antes de acontecer o primeiro evento, houve uma trilha teste à Pedra do Reino Encantado, que é um dos maiores encantos do mesmo, para com isso poder garantir o sucesso das idas dos visitantes ao lajedo.

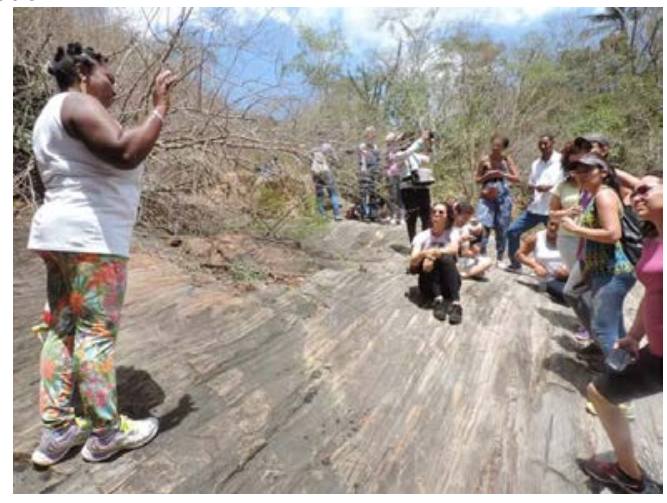

Figura 3: Trilha ao Reino Encantado - (Acervo pessoal de Luciene Tavares).

$\mathrm{Na}$ verdade, Caiana dos Crioulos sempre desenvolveu esse trabalho de turismo desde seus antepassados, porém, o visitante chegava na comunidade, as lideranças da mesma os acompanhavam, estes conheciam e usufruíam de todo o território e depois deixavam a comunidade, nem mesmo uma fotografia das tantas que haviam tirado, como lembrança para os quilombolas locais. Isso aconteceu durante muitos 
anos, e este tipo de prática precisava mudar e o despertar da comunidade veio a partir do Vivenciando Caiana.

A partir de um trabalho coletivo, passou-se a investir no turismo rural oportunizando as famílias da comunidade adquirirem uma renda através do mesmo, esta geração de renda era importante para manter as pessoas da comunidade na mesma, evitando assim as migrações e o aumento do deslocamento para outras localidades no estado ou mesmo para outros estados, principalmente a região sudeste. De acordo com Campos (2012), ao se referir aos modos como o turismo se desenvolveu e vem se desenvolvendo nos dias atuais, a autora afirma o seguinte:

Embora o turismo tenha sido alvo de diversos estudos nos últimos anos, sabe-se que a maioria das vezes, esta atividade é realizada de forma amadora, impulsionada pela ansiedade de seus estores em vivenciarem o quanto antes, os resultados e benefícios econômicos que o turismo pode trazer para a localidade. (Campos, 2012, p.57).

Como podemos ver na fala da autora, é uma realidade que não difere muito de Caiana dos Crioulos, pois as lideranças juntamente com os moradores, iniciaram de forma simples, mas organizada, modos e meios de estabelecer a divulgação, via turismo, das potencialidades que a comunidade apresentava.

O evento acontece 0 dia inteiro, é bastante festivo, contando com a a trilha ao reino encantado, que na comunidade é o local que faz parte do imaginário local, esta trilha se torna prazerosa pois acontece de forma diferenciada, pois, é desenvolvida toda em contação de história pelos condutores que são quilombolas locais.

No Palhoção, também chamado de latada (palhoça coberta de varas e palhas do coqueiro), ficam as demais atrações, como as contações de histórias desde 0 surgimento da comunidade até os dias atuais; barracas com comidas da culinária que faz parte da ancestralidade de Caiana, além das apresentações culturais como: coco de roda, ciranda, grupos de dança afro, capoeira, maculêlê, peças teatrais entre outras e também uma caminhada que sai para visitar os pontos históricos da comunidade como: o museu quilombola, a casa de farinha comunitária, e a Capela de Santa Luzia com suas passagens bíblicas expostas por quadros com pessoas negras). 


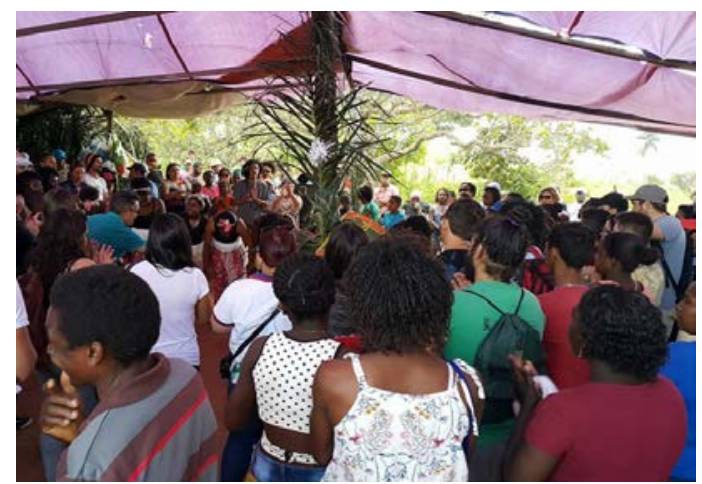

Figura 4: Momento de apresentações culturais do vivenciando caiana. (acervo de Luciene Tavares).

É um momento diverso no qual o visitante pode optar por escolher quais atividades querem participar, e com isso o quilombo de Caiana dos Crioulos, mostra aos visitantes, as tradições que fazem parte da comunidade.

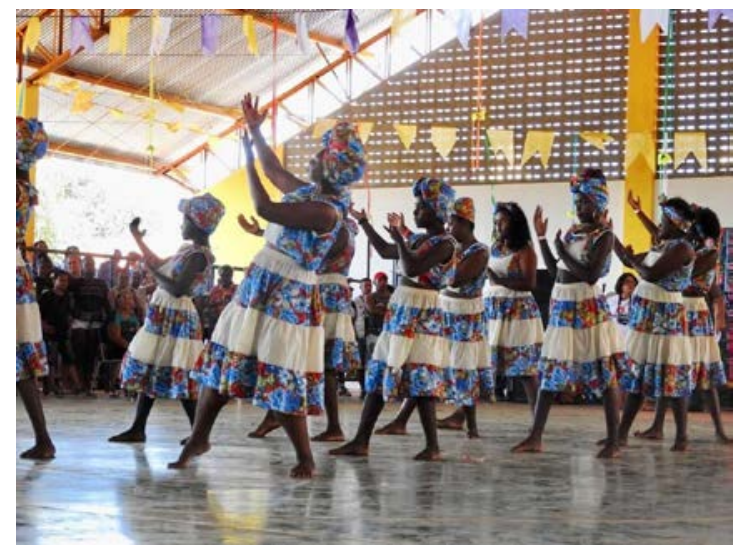

Figura 5: grupo de dança afro "cor da terra" - apresentação cultural (acervo de Luciene Tavares)

De acordo com Cruz (2016), o turismo étnico cultural tem seu trabalho com 0 entendimento de que, não é preciso a comunidade deixar suas práticas e fazeres, pelo contrário, o turismo é uma atividade de geração de renda e possibilita uma complementação das diversas atividades produtivas desenvolvidas por eles. E ainda relacionado ao turismo a autora afirma que:

O turismo é uma ação desafiadora, ainda assim quando se discute a perspectiva do turismo alternativo com o viés da sustentabilidade, ou quando se analisa a temática a 
partir dos impactos que podem vir acontecer, deste modo é importante pensar a atividade do turismo considerando a participação dos atores locais. (Cruz, 2016, p.91).

Atualmente o projeto vivenciando tem uma comissão organizadora composta por lideranças da comunidade, e uma coordenação a qual integra três destas, que foram Luciene Tavares como coordenadora geral Edinalva Rita, conhecida por Nalva, atual presidente da Associação de moradores e Elza Ursulino Presidente da Organização de Mulheres negras da comunidade, como também Severina Luzia (Cida)Coordenadora do Grupo de Ciranda e Coco de Roda "Desencosta da Parede", que é uma das nossas condutoras da trilha ao Reino Encantado .

A comunidade conta atualmente com o restaurante Rita de Chicó, que surgiu da necessidade de ter um local amplo em que os turistas pudessem se alimentar, foi então que Nalva, juntamente com seu companheiro teve a ideia deste empreendimento atraído muitos visitantes para o local.

Neste serve-se a culinária quilombola local, além de divertir os visitantes com o ecoar do toque da zabumbada tocada por Nalva. É gostoso vivenciar esses momentos em Caiana dos Crioulos, e ao se tratar deste projeto, Elza que faz parte da coordenação do mesmo, ao se relacionar a importância que esse projeto tem, afirmou que:

Bom, pra trabalhar essa questão do turismo, eu acho que ele tem uma grande valorização, uma grande vantagem, é fundamental, eu acho que o perfil, ele tem um argumento bom, o que precisa para se ter um perfil, embora algo ainda precisa muito melhorar, muito mais, muito mesmo pra gente atingir o perfil, o objetivo, mas eu acho que é legal porque, é um grupo, é um projeto que também dá ou deveria dar uma agregação bem ampla. (Elza,2020).

O vivenciando tem um papel fundamental na comunidade, pois além de trabalhar na preservação e valorização da cultura quilombola local, contribui para 0 desenvolvimento do turismo na região, gerando oportunidades de ocupação e renda para a mesma, além de ser um mecanismo impulsionador de outras atividades existentes na comunidade, como é o caso: da educação, produção agrícola, artesanais, artísticas e tantas outras.

O projeto além de ter um calendário anual, recebe visitantes também fora destes, visto que algumas visitantes não conseguem participar na data agendada pelo mesmo, e desta forma entra em contato com a coordenação e dialoga uma possível data para a equipe ou grupo está vindo vivenciar Caiana dos Crioulos.

Este tipo de prática é uma constante, principalmente com grupos de estudantes, pesquisadores, professores, por optarem sempre as visitas de segunda à sexta-feira, e como o calendário do Vivenciando está mais voltado para finais de semana, e preferencialmente aos domingos, esse público tem a opção de fazer esse contado e agendar seu dia. 


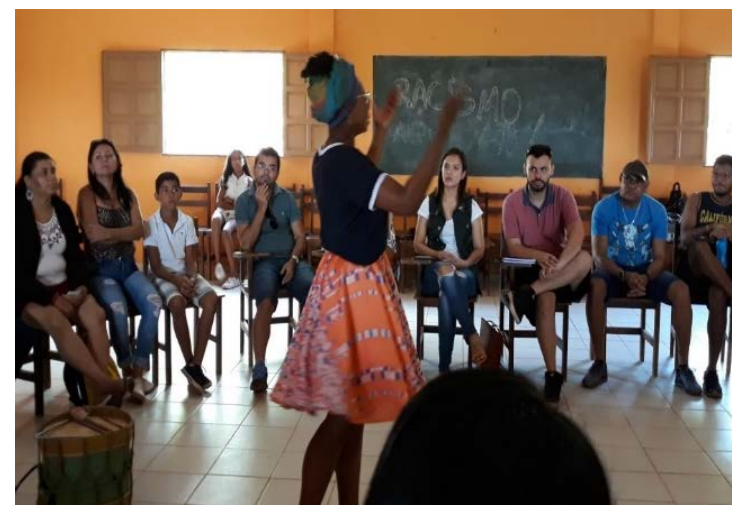

Figura 6: Universitários vivenciando caiana (acervo pessoal de Luciene Tavares).

Além de conhecerem a história do quilombo, os visitantes fazem um passeio pelo mesmo, caso faça essa opção, e tudo isso acontece de forma muito divertida, sob os sons do ecoar das vozes das mulheres caienenses e a batucada dos zabumbas deste lugar. Vivenciar Caiana é mais que um aprendizado, e sentir na pele seu berço de pertencimento e recarregar as energias de resistência do povo quilombola.

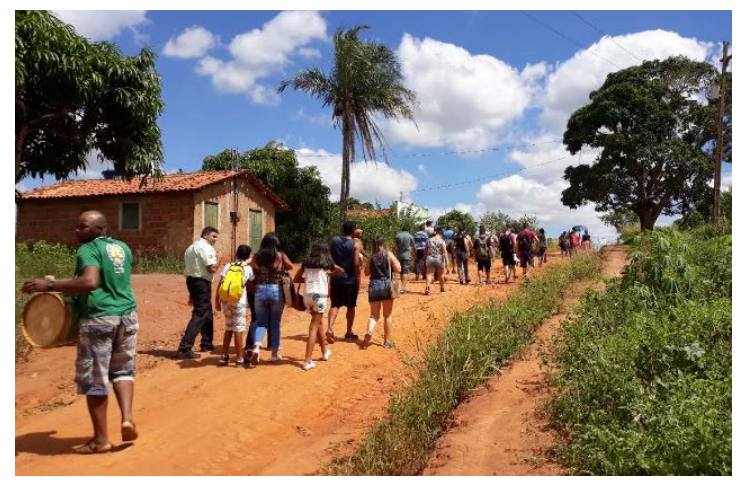

Figura 7: Universitários Vivenciando Caiana (Acervo pessoal de Luciene Tavares).

Trabalhar de forma coletiva, sempre fez parte do fazer do povo caianense, 0 despertar das mulheres nesse projeto tem um teor bastante significativo, pois são mulheres que trazem consigo toda uma ancestralidade, uma vivência cultural na comunidade. 


\section{3.-Conclusão.}

A rede de saberes que se formata através do trabalho e a ação das mulheres quilombola é um aspecto importante e norteador de mudanças sociais na comunidade de Caiana dos Crioulos. O trabalho articulado, dialógico e conjunto permitiu que o projeto Vivenciando Caiana, pudesse florir e vivificar nas suas práticas ancestrais novas maneiras de reconfigurar o desenvolvimento local, em que 0 turismo rural, apontou novas possibilidades, para gerar renda na comunidade e incentivar que as práticas culturais, as histórias que fazer parte da composição das narrativas de Caiana se reinventasse nas práticas locais.

O projeto Vivenciando e o desenvolvimento do turismo local, aquecendo a comunidade e a venda de produtos por ela gerado, contribuiu para afirmação éticoracial de Caiana, mas também para a geração de renda, aspecto fundamental na comunidade. A rede de saberes organizada pelas mulheres da comunidade através da OMNC, possibilitou e deu relevo a luta por uma inclusão dos saberes da comunidade e que fazem parte que faz parte do repertório social da comunidade contribuiu, mediatizada pelo grupo de mulheres negras do quilombo, de forma fecunda para o desenvolvimento local.

\section{4.-Referências.}

Campos, L. B. de. (2012). Potencialidade Cultural da Comunidade Quilombola de Caiana dos Crioulos para a atividade turística no brejo paraibano/ Leilane Bertoldo de Campos. - João Pessoa. Monografia (Graduação em Turismo) Universidade Federal da Paraíba - Centro de Ciências Humanas, Letras e Artes.

Cruz, F.P. (2016). O lugar do turismo no Programa Brasil Quilombola- PBQ: A experiência construída no Quilombo de Ivaporunduba no Vale do Ribeira- SP/ Francinete Pereira Cruz. Orientador Luís Carlos Spiller. Brasília,2016.1441p. Dissertação de Mestrado Profissional em Turismo. Universidade de Brasília.

Costa, I.E. (2018). Decolonialidade e Movimento quilombola na Paraíba. João Pessoa. XIX Encontro Nacional de Geógrafos.

Crenshaw, K. (2002). Documento para o encontro de especialistas em aspectos da discriminação racial relativos ao gênero. Estudos feministas, Florianopólis, v. 10, n. 1, p.171-189. Retirado de:http://www.scielo.br/pdf/ref/v10n1/11636.pdf. Acesso em:24de novembro de 2020. https://doi.org/10.1590/S0104$\underline{026 \times 2002000100011}$

Morais, S.M. (2018). Melhores quilombolas: construção e reconstrução de territórios e identidades. Dourados, UFGD. Dissertação de Mestrado. 